ARTICLE

DOI: $10.1057 /$ s41599-017-0024-1

\title{
The creative mind: cognition, society and culture
}

lb Bondebjerg ${ }^{1}$

\begin{abstract}
This article provides an overview of the main tendencies and ideas in the embodied mind paradigm in the expanding field of modern cognitive science. The focus is not on the biological and neurological aspects of cognitive science, rather the article demonstrates how basic concepts and theories from cognitive science have influenced linguistics, sociology, the understanding of art and creativity, film and film perception, as well as our understanding of historical film narratives and mediated memories. Although these areas of humanities and social science may seem unrelated, this article demonstrates how the embodied mind paradigm has actually forged links between separate scientific disciplines. Cognitive science and the embodied mind theory have created a stronger interdisciplinary connection between cognitive understanding in social science and humanities. Metaphors and image schema, the way our brain relies on narrative structures, the dynamic ability of the brain to blend old and new schemas, and the unparalleled creativity of the brain are all part of the approaches of the cognitive social science and humanities to social interaction, communication and creativity described here. The article also discusses the relationship between the more universal dimensions of the human mind and the question of cultural and social variations. The argument here is that a cognitive and more universal theory of human beings is not the same as determinism. On the contrary, when we understand our universal commonalities and the basic functions of our embodied mind we will also be better placed to understand cultural and social differences and variations.
\end{abstract}

\footnotetext{
${ }^{1}$ Department of Media, Cognition and Communication, University of Copenhagen, Copenhagen, Denmark. Correspondence and requests for materials should be addressed to I.B. (email: bonde@hum.ku.dk)
} 


\section{Introduction}

$\mathrm{t}$ ought to be an established fact in all sciences that human beings are the result of a long evolutionary development with interaction between our biology and the social and cultural conditions under which this evolution has taken place. Yet, in some sciences to point to biology, genes and the way our brain is basically constructed as part of an argument of social interaction or culture and creativity can still raise anger and controversy. The fact that our mind is embodied, that our language, way of thinking, our way of interacting with each other, our gender is firmly based in our bodies and our brain can still lead to heated discussions in some branches of academia. Yet, all important forms of cognitive science have clearly pointed out that it is not a question of biology and human nature against culture and society. It is in fact a question of understanding the very complex interaction between nature, society and culture-in line with a pretty long tradition from Darwin onward (see Bondebjerg, 2015).

\section{Mapping the field of cognitive science}

In one of the early, seminal books on cognitive science, Francisco J. Varela, Evan Thompson and Eleanor Rosch's The Embodied Mind. Cognitive Science and Human Experience (1991) even the title indicates this. From the first sentences of the introduction they state that their aim is to define cognitive science as something that combines an understanding of the lived human experiencefollowing the philosophy of Merleau-Ponty-with a biological understanding of the brain. The main point is that we need to:

(..) see our bodies both as physical structures and as lived experiential structures - in short, as both 'outer' and 'inner', biological and phenomenological. The two sides of embodiment are obviously not opposed. Instead, we continuously circulate back and forth between them" (Varela et al., 1991, p 15).

When writing this, the three authors make a statement, which they at the same time see as criticism of a dominant tendency in early forms of cognitive science to largely ignore this interaction between cognition, society and culture. This fundamental interaction is however also absent from most forms of human and social sciences, where a strong tendency towards social constructivism has dominated for decades. Taken to a just as fundamentalist level as early cognitive science, social constructivism tend the claim that all social and cultural phenomenon are constructions, that in other words cognition and the embodied mind means very little. What Varela, Thompson and Rosch intend to do with their book is in their own words not to

(...) build some grand unified theory (...) our concern is to open a space of possibilities, in which the circulation between cognitive science and human experience can be fully appreciated" (Varela et al., 1991, p 18).

Varela, Thompson and Rosch map the field of cognitive science by pointing to five main areas (Varela et al., 1991, 7): Neuroscience, the central medical science area, Cognitive psychology, Philosophy and Artificial intelligence linguistics, and philosophy. So even at this early stage of mapping a relatively new field, we see the merging of disciplines across natural and medical sciences and social sciences and humanities. It takes at its starting point the fundamental structures of our brain and how it works and combines it with the interaction between brain and body in the world of human experience, interaction, and communication. So even though basic neuroscience and artificial intelligence could seem to generate the image of cognitive theory and the human mind as a computer this is quite wrong. As both neuroscientist themselves and the uses of basic cognitive theory in social sciences and the humanities demonstrate, our brain and the way it interacts with culture and society is amazingly creative and flexible.

\section{Metaphors we think with and live by}

Today the fields of cognitive studies described by Varela et al. would have to be expanded because communication sciences in a broad sense, film and media studies and studies of art and literature has now been directly inspired by cognitive psychology and science. This can partly be explained by the influence of Gerorge Lakoff and Mark Johnson beyond linqustics, but also by cognitive studies of creativity, aesthetic and the arts. Varela et al.'s book is already quite unusual as a basic introduction to cognitive science by including phenomenology and aspects of non-western philosophy, especially the Buddhist notion of mindfulness (Varela et al., 1991, 23f). Very neurological representations of the brain and how it works is combined with more experiental dimension of our mind. But such dimensions also link to Lakoff and Johnson's seminal founding of a cognitive linguistics in which traditional understandings of language are replaced by an embodied theory where language is seen as part of an embodied mind.

George Lakoff and Mark Johnsons book Metaphors we live by (1980) is a very early and extremely important book, because it turned linguistics and thus central parts of the humanities completely upside down. There is a direct link to Varela, Thompson and Rosch's basic attempt to move cognitive science towards the study of the interaction between basic cognitive and embodied structure and our lived experience. Taking metaphor away from just poetic language and into the centre of everyday language and ways of thinking, Lakoff and Johnson not just went against traditional linguistics but also against the sharp line between rationality and emotion in Western thought and philosophy. What the book suggested was that our language and our way of thinking was embodied, and in some of their later writings this notion was further expanded through the discovery of the role of mirror neurons, and the role they play in explaining how language and metaphors were indeed embodied, changed and developed into networks of meaning structures (Lakoff, 2008).

Just as Varela et al. start from a computational understanding of the brain, Lakoff and Johnson use this, not just to anchor the understanding of language in our brain but to demonstrate how very basic neural mechanisms serve pretty complicated mental and linguistic processes that dominate in both everyday language, poetic language and more abstract thinking and reasoning. "We think with our brains. There is no other choice. Thought is physical. Ideas and the concept $s$ that make them up are physically 'computed by brain structures. Reasoning is the activation of certain neuronal groups in the brain given prior activation of other neuronal groups (Lakoff, 2008, p 17) The neurological starting point allows Lakoff to describe more precisely how connectivity via the brain works in our language and way of thinking. The brain is a complex of regions and neurons that structure input and output, and as Lakoff points out "neurons that fire together, wire together (Lakoff, 2008, p 19). This basically means that metaphors and metaphorical networks are built in our mind in such a way that certain metaphorical connections are stronger than others, although it also means that in our everyday interaction with the world, metaphors are constantly changed, developed or modified.

In 1980 when Metaphors we live by came out neuroscience and cognitive psychology was not as far advanced as today, where the mapping of the brain and how the embodied mind functions has taken giant leaps. The move towards a stronger embodied mind theory of linguistics was however taken quite a bit further in 
Mark Johnson's The Body in the Mind. The Bodily Basis of Meaning, Imagination and Reason (1987). Here the criticism of traditional objectivist linguistic theories of meaning went even deeper and they formulated a broader, embodied theory of imagination, metaphor and meaning. The theory of imagination, metaphors and image schema in linguistics point to communication and film studies and there are clearly many interdisciplinary dimensions in Lakoff and Johnson's writings. We find the same kind of theoretical main focus in for instance David Bordwell's seminal book Narration in the Fiction film (1985) in which cognitive schema theory is used to explain different narrative structures in film and how viewers actively perceive a film. Also here the embodied mind theory is crucial. In Philosophy in the Flesh. The Embodied Mind and its Challenge to Western Thought (1999) they argue for an embodied philosophy, and in George Lakoffs Moral Politics. How Liberals and Conservatives Think (2016) he moves into media and political communication.

Lakoff and Johnson's intervention into linguistics, communication and philosophy illustrate the potential strength of cognitive science to form a basis for ways of articulating, analysing and understanding central areas of society and culture in different disciplines. Their study of metaphor and the whole embodied dimension of language and thought again underlines the interaction between our bodily capacities and the sensori-motoric aspects of our embodied mind and the context we act in. There is therefore a clear link between cognitive linguistics and the basic dimensions in cognitive science as such. In their description of cognition as embodied action Varela et al. call such cognitive theories another way of avoiding the chicken-egg paradox of cognition: the world does neither exist out there with pre-given properties, nor is the world just a projection of our internal system. The interaction between world (chicken) and embodied mind (egg) is such that the interactions forms a new whole:

Cognition depends upon the kinds of experience that come from having a body with sensorimotor capacities, and second that these sensorimotor capacities are themselves embedded in a more encompassing biological, psychological and cultural context (...) sensory and motor processes, perception and action, are fundamentally inseparable in lived cognition (1991, 172f).

\section{Cognitive sociology: the perception of self and others}

In cognitive science the relation between the brain, the body and the social and cultural context is crucial, it is the interaction between the embodied human mind and our everyday experience, which is in focus. This means that our interaction with other humans is crucial, and the way we understand and experience our own self and that of others of equally strong importance. Such questions are classical questions in philosophy, which have taken new forms in both philosophy and in psychology and sociology under the influence of cognitive science.

Psychology and psychoanalysis have, since the days of Freud and Jung, been a varied, scientific field of their own, but have also inspired other areas-especially in the social sciences and humanities. With the vastly increased empirical and clinical data on how the brain and the embodied mind work, the field that used to be social psychology has moved in the direction of a broader field of cognitive sociology - and so has psychology in general. In one of the first major books aiming at changing the focus of traditional psychology, Marvin Minsky's The Society of Mind (1985), even the title indicate that the study of the mind is seen metaphorically as a both physical and social construction. In his postscript Minsky defines the central concept of the book as being "that the mind is a society of many smaller mechanisms'
(Minsky, 1985, p 323), mechanisms that work together to create for instance memory, learning sensory experiences or our understanding of ourselves as a self and our understanding of others.

Minsky's background is artificial intelligence at MIT, and the way he writes about the mind is clearly influenced by thinking in practical terms about models that could be implemented in computers to simulate the human mind. The two authors of one of the most used textbooks in cognitive sociology Social Cognition (1984, 5th edn, many revised new editions), Susan T. Fiske and Shelley E. Taylor, came out of mainstream American psychology, and the book was written explicitly to counteract the dominance of behaviourism. In the introduction the two authors define the field of social cognition as "the study of how people make sense of other people and themselves. It focuses on how ordinary people think about people and how they think they think about people" (Fiske and Taylor (1991, p 1). The book goes through attribution theory, that is how we ascribe value, meaning and causality to social events, through the important social categories and schemas we use in a top down way to understand both others, ourselves and social actions. There is a focus on how we perceive our selves and the role of memory and emotions and the forming of attitudes. Compared to traditional psychology cognitive processes play a fundamental role, although the book was written at a time where modern neuroscience and cognitive studies was not as advanced as today.

Fiske and Taylor's book on social cognition is part of a wider move towards what you might call a more universal cognitive sociology. At least that is what Eviatar Zerubavel (1997) argues for in his short but interesting book, Social Mindscapes. An Invitation to Cognitive Sociology. He argues that in light of the new developments in neuroscience and cognitive psychology, we need to stress "the cognitive commonality" between all human beings. The cognitive trend, as Zerubavel points out, moves away from the almost romantic notions of the specificity of the individual towards an endeavour to "discover universal patterns in the way we form concepts, process information, activate mental 'schemas', make decisions, solve problems, generate meaningful sentences from 'deep' syntactic structures, access our memory, and move through the various stages of our cognitive development" (Zerubavel, 1997, p 3).

However, Zerubavel also warns against a too strong and rigid cognitive universalism, and argues for the interaction between what he calls the collective subcultures linked to social and cultural structures, which influence the way we think. In the same way he argues for a stronger focus on also cognitive individualism. His aim is clearly to link the understanding of the individual cognitive mind and the social cognitive mind with the more universal mind that are common to the whole of mankind. In this sense he continues the trend in cognitive studies to undermine any simple determinism in the understanding of the relation between our universal mind and the social and cultural context this mind of ours is living. Zerubavel wants us to pay more attention to "cognitive diversity" and "cognitive subcultures".

We must be aware of universal commonalities based on how our mind and body function, no matter who we are and where we are. At the same time we must not ignore that the process of "cognitive socialisation that allows us to enter the social, intersubjective world” (Zerubavel, 1997, p 15).

Such studies have in fact already appeared, for instance Nicholas Christakis and James Fowlers fascinating study of social networks, Connected. The Amazing Power of Social Networks and How They Shape Our Lives (2009). Based on rich data on how people on social networks connect, they clearly show how technologies in general are built on the same principles as those we 
know real life and traditional theories and studies of cognitive sociology. Connections and networks are based on social and cultural proximity and similarities, and very often emotions pay a central role. Our contacts are based on mirror-acts, and the fundamental way we form networks, even in this hi-tech complex world of ours, are deeply structures by rules and mechanisms that have evolved over a long time of genetic evolution. In their book they exemplify this by studying political networks in several parts of the world. Looking at for instance the Iranian political blogosphere and the American we find exactly the same structure. The networks on the social media in both countries are similar to social and political networks in real life. We connect and talk to those we are alike and agree with already, so social networks only to a very small degree expand our network to people we do not know or already agree with (Christakis and Fowler, 2009, 172ff)

Networks, according to Christakis and Fowler, may therefore seem very creative and different from the kinds of networks we have seen before, but in reality they are expansions and variations of rather fundamental, evolutionary mechanisms of social interaction:

We deliberately choose to form social connections with specific individuals, with whom we share greater or lesser intimacy and affection, for brief or lengthy periods of time. And unlike other social species, we have a special capacity to imagine what others are thinking and feeling, including what they are thinking of us. Our embeddedness in social networks means that we must cooperate with others, judge their intentions, and influence or be influenced by them (Christakis and Fowler, 2009, p 214).

\section{Blending theory and our creative mind}

Cognitive science is perhaps often seen as a rather simplifying theory and way of understanding humans and the way humans interact with the world and each other. However, as we have seen with cognitive linguistics and sociology, the basic cognitive understanding of communication and social encounters is clearly used to develop quite complex and dynamic models of the human mind and human activities. The fundamental call for a combination of a neurological and biological understand of the embodied mind with the human experience in all its dynamic cultural and social experience and diversity we find in Varela et al. and in many other hard core books on cognitive science is developed fully in other areas where a cognitive approach is used. One of the most interesting developments in creative theory that builds of basic cognitive science is Mark Turner and Gilles Fauconnnier's theory of conceptual blending in thinking in general and production of art specifically. There is a direct link between Varela et al.'s general cognitive theory and Lakoff and Johnson's cognitive linguistics. The basic principle of blending is connected to the theory of neurological metaphorical networks and to schema theory in the sense that blending theory is trying to explain how basic schematic structures make very complex and dynamic variations possible.

As Turner and Fauconnier point out, humans have developed an exceptionally flexible and creative mind and many aspects of the working brain and the embodied mind cut across different activities in our everyday life and work. However, recently special attention has been paid to the creative brain, more specifically in art, film and media. If art and creativity is about creating something new, this must in some way activate many and also different part of our brain and the ways of thinking we have already embedded in our brain. We know that part of our mind works top down to activate established schemas, which can help us solve specific problems or interpret a concrete social event. We use what is already stored to navigate our reality. However, creativity is also about creating new schemas and combining schemas we already have in new ways. Fauconnier and Turners main point is in fact that all humans are constantly developing the conceptual neural networks we already have.

Gilles Fauconnier and Mark Turner have worked intensely with this and what they call "conceptual blending", especially in their book The Way we Think. Conceptual Blending and the Mind's Hidden Complexities (2002). Their claim is in fact that approximately 50,000 years ago, during the Upper Palaeolithic period, a spectacular change took place, during which human beings "developed an unprecedented ability to innovate. They acquired a modern human imagination, which gave them the ability to invent new concepts and to assemble new and dynamic mental patterns" (Fauconnier and Turner, 2002, p 5). This ability, called conceptual blending, is thus a general feature of the modern human brain and mind, it is what makes it possible for humans to develop large and very complex conceptual networks, and also to develop, change and renew them. In their understanding, this is not just central to art, but something that underlies all our mental activities from language, art and science and down to basic everyday social skills.

In a later edited book by Mark Turner, The Artful Mind. Cognitive Science and the Riddle of Human Creativity (2006) focus is on how specifically to understand creativity in art forms, and how this is related to our general ability to deals with quite complex neural networks in our life in general. In all articles in the book we find a clear tendency to unite universal cognitive patterns with more group based, even individual forms of social and cultural cognition:

The individual human being, in form and movement, in thought and action, is a seamless intersection of powerful histories-phylogenetic history, individual development, and social and cultural history-all profoundly influential. A human being is a unified agency of biology, psychology, and social, environmental and cultural patterns (Turner ed. 2006, p 16).

Therefore, even though all humans come with a body and a brain which has a lot of pre-installed 'hardware' based on a long evolutionary development, even though we are not in that sense socially and culturally constructed, the bottom line in the theory of the creative mind and blending theory is that we develop new networks all the time. The fundamental dimensions of language, of telling stories and making pictures, which is part of our evolutionary history, is all there in our embodied and creative mind from the day we are born. Yet, we do not all become great artists, authors or filmmakers. The mix of genes, biology, evolution and our social and cultural history as individuals and in families and cultural groups is what shapes and forms a creative mind in such a way that this individual changes history and our way of looking at ourselves, others and the world. This is the magic of the creative mind, the magic blending of the embodied mind, society and culture.

\section{Film, narrative and cognition}

Fauconnier and Turners theory of blending and creative work is in many ways exemplified by the way in which cognitive film theory developed from the 1980s and on. Until then film theory was mostly influenced by structuralism or more classical aesthetic approaches to the historical and genre based study of film. However, almost at the same time as Lakoff and Johnson started changing our fundamental understanding of language by combining cognitive theory and more formal and structural forms of understanding, David Bordwell combined formal analysis and cognitive psychology in the study of film. In Narration in the Fiction film (1985) Bordwell discussed classical theories of film 
narration with a new focus on the psychology of film perception and cognition. The inclusion of the viewer perspective was important and novel for film theory because Bordwell clearly pointed out that a film is both made by the director and other creative people and the viewer, and that the system behind film narration and the viewers perception is based on perceptual and cognitive dimensions of a more general nature. Watching a film was in Bordwell's theory of narration a cognitive and emotional process and experience, and using a just formal-aesthetic approach to film was not enough.

Bordwell's way activating the process of viewing film was a direct critique of the dominant film theories which tended to talk about film that positioned the viewer in a specific ideological way. Instead Bordwell saw the film as a way of cueing the spectators, creating an active interaction between our already existing mental schemas and the specific film. Narration thus became an intense meeting point between a film and a viewer, based on a series of psychological and cognitive procedures:

The fabula is thus a pattern, which perceivers of narratives create through assumptions and inferences. It is the developing result of picking up narrative cues, applying schemata, framing and testing hypothesis (...) The viewer builds the fabula on the basis of prototype schemata (identifiable types of persons, actions, locales etc.), template schemata (principally "the canonic story") and procedural schemata (a search for appropriate motivations and relations of causality, time and space) (Bordwell, 1985, p 49).

Bordwell combined this more formal, structural, psychological and cognitive approach to film with a more concrete historical definition of basic forms of narration: Classical narration is basically the Hollywood mode of narration and at the same time a rather canonic form with a strong position as universally understandable; Art cinema narration on the other hand is a historical type of narration, which challenges the canonical form of narration. Bordwell also discussed other forms like Historical-Materialist narration in early Soviet cinema, and what he called parametric narration. Again we see a combination of more basic cognitive forms of psychology and concrete historical and aesthetic analysis situating the cognitive dimensions in a social and cultural context.

Bordwell is a founding father in cognitive film theory, building connections to also more aesthetic and historical forms of film theory and film history. Today cognitive film theory has developed into the most comprehensive theory of film. Another important figure is Torben Grodal whose work is based on an evolutionary understanding of how film genres interact with our emotional and cognitive structures. His two books Moving Pictures. A New Theory of Film Genres, Feelings and Cognition (1996) and Embodied Visions. Evolution, Emotion, Culture and Film (2009) are both key texts in modern, cognitive film theory. Grodal's first book was in many ways similar in general approach to Joseph Anderson's The reality of Illusion: An Ecological Approach to Cognitive Film Theory (1996) in the sense that they draw on the large scale evolutionary perspective. Here the premise is that the narrative and other schemata we use in film viewing have an effect on our general real life experience:

(..) the schemata we bring to films are those we bring to other experiences in the world and when the viewing experience modifies those schemata (as all perceptual and cognitive cycles do) it has in some ways change the way we interact with the world (Anderson 1996, p 155).

The cognitive theory of film and film narratives see the filmic form and filmic genres as specific domains of art and communication. Genres are-as Grodal point out in his works-ways of integrating human characters, actions and emotions, which can be seen as film forms and filmic representations of real life. Genres are however also modalities of narration and emotions that build on and interact with real life experience and draw on our embodied mind structures. Melodrama is quite distinct from romantic comedy or from action-adventure movies for instance, however the narrative and emotional structures point us back to networks of meaning and experiences in our embodied mind. Just as Bordwell stressed the relation between film form and genre and the cognitive aspects of the spectator, Grodal already in his first book pointed to

(..) a systematic relation between the embodied mental processes and configurations activated in a given type of visual fiction and the emotional 'tone' and 'modal qualities of the experienced affects, emotions and feelings in the viewer. Prototypical genres of visual fiction will evoke typical tones and modalities (..) (Grodal, 1996, p 3)

Putting the embodied mind in the context of film viewing therefore also leads to an alignment between cognitive structures and emotions in reality and in film. As Lakoff has pointed out (Lakoff, 2008, pp 27-28, see also Bondebjerg, 2014) narratives, even complex narratives, are not just something we find in language, film and literature, they are in fact central cognitive structures of the world of fiction and non-fiction and our way of experiencing our everyday reality. Frames and scripts are cognitive schemata, and they are used all the time to structure mediated experiences and real life events. Narrative then, is in fact also a result of evolution, it is a cognitive schema we all possess and which is part of the way we understand reality and create meaning based on characters, space, events, time and causality. Life around us, the people we meet and the actions and events we are involved in are constantly interpreted by our narrative 'gene' to make stories of others, just as our own life and self is reflected in a constantly updated self-narrative (Bruner, 1996 and 2002, Gottschall, 2012).

\section{History, memory and film}

Memory is one of the most debated issues in cognitive theory, and in memory studies more broadly. The cognitive procedures and functions of memory are crucial to our way of experiencing a coherent self over time and for our ability to navigate in the present. In a paradoxical way then, the past is in many ways a very important part of the present. Memory researchers like José van Dijck (2007) and Astrid Erll (2011) point out that our brain stores data on the past from both fiction and non fiction sources, from real life experience and mediated experience in such a way that they are mixed or interact in various ways. Stories affect our minds and memories, fiction teaches us facts about the world, and as Gottschall states: 'fiction has probably told us as much about the world as anything else' (Gottschall, 2012, p 149).

Fiction needs to be taken seriously as a factor influencing the human mind and our individual and collective memory. But looking at the concept of memory, we can even take this much further. First of all, memory is extremely important both on and individual level and a collective social level. Without memory we loose feeling of who we are and our social ability to navigate in society disappears. In José van Dijck's Mediated Memoirs in the Digital Age (2007) he simply states that:

Remembering is vital to our well-being, because without our autobiographical memories we would have no sense of past or future, and we would lack any sense of continuity. Our image of who we are (...) is never stable but it is subject to constant remodelling because our perceptions of who we are change along with our projections and desires of who we want to be (Dijck, 2007, p 3). 
He combines this observation with a reference to Susan Bluck's (2003) definition of the three main functions of autobiographical memory: preserving the sense of being a coherent person over time; strengthening social bonds by sharing personal memories; and using past experiences to construct models to understand inner worlds of self and others.

As we all know from experience, memory is imperfect, seen from an objective point of view. We constantly forget things and happenings in the past, or we interpret the same things differently. As Gottschall formulates it: when we try to recall something in the past we are not just simply "queuing up a videotape; we recall bits of data from all around the brain. These data are then sent forward to the storytelling mind (...) who stiches and pasts the scraps and fragments into a coherent and plausible recreation of what might have occurred' (Gottschall, 2012, p 169). In other words the past as it is represented in our mind is a 'mental simulation'- not mere fiction, not without a firm base in actual past experiences, but a narrative, a 'fictionalisation.' The neurological, biological background for this can be found in the fact that memory is not located in one specific part of the brain, as Dijck points out:

The establishment of memory depends on the working of the entire brain network, consisting in turn of several memory systems, including semantic and episodic memory, declarative or procedural memory (...) the brain is thus the generator of reflexes, responses, drives, emotions and ultimately, feelings; memory involves both the perception of a certain body state and a certain mind state' (Dijck, 2007, p 31).

Memory is not just individual, it has a clear collective dimension and social function. This collective and social form of memory has always been around, but since this form of memory to a large degree includes mediated forms, the rise of audio-visual and digital media with vast archive functions have changed our access to collective memory. In an article with the title ' A Cognitive Taxonomy of Collective Memory' the two cognitive psychologists David Manier and William Hirst (2008) divided the forms of collective memory into three: collectiveepisodic memory, the form of collective memory shared by a specific social group (including families); collective-semantic memory, the form of collective memory persons or groups can have about past and historic events and times they do not have personal experience of themselves, but where the memory is based on narratives from others and mediated narratives; Collectiveprocedural memory, the form of collective memory which is situated around collective and institutional rituals and thus connected with traditions of remembrance. This distinction between individual and collective memory and the different forms of memory is of course not a sharp division. The different domains and forms of memory interact in any individual's memory. As individuals we are part of a broader social and cultural context, and collective memories-for instance in the form of mediated collective narratives-mingle with personal memories.

In modern times, after the rise of television, film and new digital media, one could argue that mediated forms of memory has become so important that it is necessary to define a new mode of public cultural memory. This is precisely what Alison Landsberg has argued-following the already mentioned work of José van Dijck-and she calls this "prosthetic memory" in her book Prosthetic Memory. The Transformation of American Remembrance in the Age of Mass Culture (2004). She defines this form of mediated memory as something emerging "at the interface between a person and a historical narrative about the past" (Landsberg, 2004, p 2) and she elaborates further on the nature of this merging:
In the process I am describing, the person does not simply apprehend a historical narrative but takes on a more personal, deeply felt memory of a past event through which he or she did not live. The resulting prosthetic memory has the ability to shape that person's subjectivity and politics (ibid.)

\section{Conclusion}

The understanding of the brain and the biology behind the concept of the embodied mind is no longer a case for the medical sciences, for neuroscience and medicine, nor for the high tech versions of artificial intelligence. If the understanding of a cultured person used to be one that knew history, literature and the arts, one might suggest that today more than ever, we also need to know the basics of how our mind and body work. From linguistics to the creative arts, from psychology to sociology, from history and memory studies to studies of mediated networks and communication, the insight of cognitive theory has made a deep impact on traditional areas of research.

The impact of cognitive theory on for instance the humanities and social science is still heavily debated, and many researchers tend to see cognitive theory as reductionist and deterministic in the understanding of culture and society. Although such positions can be found in cognitive theory, my presentation of main tendencies in the development of the theory of the embodied mind clearly shows a different picture. It seems that most of the prolific researchers in this tradition are very much aware of the dynamic relations between the brain, the mind, and the body as a biological phenomenon and the cultural and social context. There is in fact a very nuanced understanding of the way rather firmly, evolutionary elements in our body and brain has been influenced and is constantly influenced by evolution and by our individual and group oriented cultural and social actions and experiences. Needles to say, that such a fundamental understanding of the interaction between body, brain and our social and cultural environment is based on the understanding of evolution, Darwin started. It is probably the best supported scientific hypothesis in modern history.

To just ignore cognitive and evolutionary theory would be a major mistake, the embodied mind theory is in fact one of the most promising theories in a long time. It is a theory that has the potential to make researchers from very different disciplines speak on the basis of a common framework for the understanding of man in culture and society. It is not the grand theory to end all other theories, but it is theory that in many ways celebrates and explains why humans have what Fauconnnier and Turner has described as a fantastic creative mind, and what can make the neuroscientist Anton Damasio become quite poetic:

And what is the ultimate gift of consciousness to humanity? Perhaps the ability to navigate the future in the seas of our imagination, guiding the self craft into a safe and productive harbour. The greatest of all gifts depends once again, on the intersection of the self and memory. Memory, tempered by personal feeling, is what allows humans to imagine both individual well-being and the compounded well-being of a whole society, and to invent the ways and means of achieving and magnifying that well-being (Damasio, 2012, pp 296-97).

Cognitive science has developed into one of the most important core sciences for the understanding of the embodied, human mind. Step by step neurology uncovers new aspects of how the brain works and how the different regions and part of the brain collaborate. We know by know that it is an extremely complex, dynamic and creative brain evolution has given us, and we also know that ancient ways of understand the relation between mind and body, 
and between rationality and emotion can no longer be sustained. This means that cognitive science has already had fundamental influence on how we look at humans and consequently also how humans, culture and society interact. Cognitive science and the embodied mind theory has been very influential in creating link across various academic disciplines-although it is also still controversial in some parts of humanities and social science.

In this article I have tried to give an overview of basic elements in cognitive science with a special focus on key concepts like schemata in social and communicative interaction, metaphors and neural networks, narrative, creativity and memory and historical narratives. Taken from basic cognitive science such concepts have played an important role in changing the way social sciences and humanities look at culture and society. A main point in this connection is that cognitive science does not rest on a deterministic notion of the human brain, on the contrary. Cognitive science and modern neurology consider the interaction between the embodied mind and the social and cultural context to be of extreme importance. It is a highly dynamic interaction in which pre-established structures of the brain 'negotiate' with and constantly change and develop in connection with the experiences we have as individual, human beings in a specific cultural and social context.

As the leading American neurologist, Antonio Damasio, has stated:

Naturalising the conscious mind and planting it firmly in the brain does not diminish the role of culture in the construction of human beings, does not reduce human dignity, and does not mark the end of mystery and puzzlement. Cultures arise and evolve from collective efforts of human brains, over many generations, and some cultures even die in the process. They require brains that have already been shaped by prior cultural effects. The significance of cultures to the making of the modern human mind is not in question (Damasio, 2012, p 29).

Received: 14 September 2017 Accepted: 11 October 2017

Published online: 31 October 2017

\section{References}

Anderson JD (1996) The Reality of Illusion: An ecological Approach to Cognitive Film Theory. Southerns Illinois University Press, Carbondale

Bluck S (2003) Autobiographical memory: exploring Its functions in everyday life. Memory 11(2):113-123

Bondebjerg $\mathrm{Ib}$ (2014) Documentary and cognitive theory: Narrative emotion and memory. In Media Commun 2(1):13-22

Bondebjerg, Ib (2015) The embodied mind: when biology meets culture and society. In: Palgrave Communications, https://doi.org/10.1057/palcomms. 2015.15

Bordwell d (1985) Narration in the fiction film. University of Wisconsin Press, Madison, WI

Bruner J (1996) Actual minds, possible worlds. Harvard University Press, Cambridge, MA

Bruner J (2002) Making stories. Law, literature, life. Harvard University Press, Cambridge, MA

Christakis N, Fowler J (2009) Connected. The amazing power of social networks and how they shape our lives. Harper Press, Hammersmith, London
Damasio A (2012) Self comes to mind. Constructing the conscious brain. Vintage Books, New York

Dijck José van (2007) Mediated memories in the digital age. Stanford University Press, Stanford

Erll A (2011) Memory in culture. Palgrave Macmillan, Basingstoke

Fauconnier G, Turner M (2002) The way we think. Conceptual blending and the mind's hidden complexities. Basic Books, New York

Fiske ST, Taylor SE (1991) Social Cognition, 2nd edn. McGraw-Hill, New York

Gottschall J (2012) The storytelling animal. How stories make us human. Mariner Books, Boston

Grodal T (1996) Moving pictures. A new theory of film genres, feelings and cognition. Oxford University Press, Oxford

Grodal T (2009) Embodied visions. Evolution, emotion, culture and film. Oxford University Press, Oxford

Johnson M (1987) The body in the mind. The bodily basis of meaning, imagination and reason. University of Chicago Press, Chicago

Lakoff G (1988) Cognitive semantics. In: Eco U, et al. (eds) Meaning and mental representation. Indiana University Press, Bloomington

Lakoff G (2008) The neural theory of metaphor. In: Gibbs R (ed) The Cambridge handbook of metaphor and thought. Cambridge University Press, Cambridge, pp 17-38

Lakoff G (2016) Moral politics. How liberals and conservatives think. University of Chicago Press, Chicago

Lakoff G, Johnsons M (1980) Metaphors we live by. University of Chicago Press, Chicago

Lakoff G, Johnson M (1999) Philosophy in the flesh. The embodied mind and its challenge to western thought. Basic Books, New York

Landsberg A (2004) Prosthetic memory. the transformation of american remembrance in the age of mass culture. Columbia University Press, New York

Manier D, Hirst W (2008) A cognitive taxonomy of collective memory. In: Erll A, Nünning A, Young SB (eds) Cultural memory studies: an international and interdisciplinary handbook. de Gruyter, Berlin/New York, p 253-262

Minsky M (1985) The society of mind. Touchstone Books, New York

Turner M (2006) (ed) The artful mind. Cognitive science and the riddle of human creativity. Oxford University Press, Oxford

Varela FJ, Thompson E, Rosch E (1991) The embodied mind. Cognitive science and human experience. MIT Press, Cambridge, MA

Zerubavel E (1997) Social mindscapes. An invitation to cognitive sociology. Harvard University Press, Cambridge, MA

\section{Data availability}

Data sharing is not applicable to this paper as no datasets were analysed or generated.

\section{Additional information}

Competing interests: The author declares no competing financial interests.

Reprints and permission information is available online at http://www.nature.com/ reprints

Publisher's note: Springer Nature remains neutral with regard to jurisdictional claims in published maps and institutional affiliations.

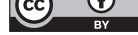

Open Access This article is licensed under a Creative Commons Attribution 4.0 International License, which permits use, sharing, adaptation, distribution and reproduction in any medium or format, as long as you give appropriate credit to the original author(s) and the source, provide a link to the Creative Commons license, and indicate if changes were made. The images or other third party material in this article are included in the article's Creative Commons license, unless indicated otherwise in a credit line to the material. If material is not included in the article's Creative Commons license and your intended use is not permitted by statutory regulation or exceeds the permitted use, you will need to obtain permission directly from the copyright holder. To view a copy of this license, visit http://creativecommons.org/ licenses/by/4.0/.

(C) The Author(s) 2017 